\title{
Detection of Low Pathogenicity Influenza A(H7N3) Virus during Duck Mortality Event, Cambodia, 2017
}

\author{
Annika Suttie, Sokhoun Yann, Phalla Y, \\ Sothyra Tum, Yi-Mo Deng, Vibol Hul, \\ Viseth Srey Horm, lan Barr, Andrew Greenhill, \\ Paul F. Horwood, Kristina Osbjer, \\ Erik A. Karlsson, Philippe Dussart
}

In January 2017, an estimated 3,700 (93\%) of 4,000 Khaki Campbell ducks (Anas platyrhynchos domesticus) died in Kampong Thom Province, Cambodia. We detected low pathogenicity avian influenza $A(H 7 N 3)$ virus and anatid herpesvirus 1 (duck plague) in the affected flock; however, the exact cause of the mortality event remains unclear.

\begin{abstract}
A vian influenza viruses (AIVs) are negative-sense, single-stranded RNA viruses normally found in wild aquatic birds, the natural reservoir (1). Typically, AIVs do not cause severe disease in domestic poultry; however, 2 AIV subtypes, H5 and H7 influenza A viruses, are capable of mutating to form highly pathogenic avian influenza (HPAI) variants that can cause high rates of disease and death in poultry flocks (2). In addition, establishment of AIVs in domestic poultry increases the probability of zoonotic transmission to humans. Recent attention has focused on H7 AIVs (particularly subtype H7N9 in China) that have become established in domestic poultry and repeatedly transmitted to humans since 2013 (3). Influenza A(H7N3) and $\mathrm{A}(\mathrm{H} 7 \mathrm{~N} 7)$ viruses have also been the causative agent in historical poultry and human infections in Europe and the Americas (2). Overall, the pathogenic and zoonotic potential of $\mathrm{H} 7$ strains makes them a substantial economic and public health concern.
\end{abstract}

Author affiliations: Institut Pasteur du Cambodge, Phnom Penh,

Cambodia (A. Suttie, S. Yann, P. Y, V. Hul, V.S. Horm,

E.A. Karlsson, P. Dussart); Federation University, Churchill,

Victoria, Australia (A. Suttie, A. Greenhill); National Animal Health

and Production Research Institute, Cambodia Ministry of

Agriculture, Forestry and Fisheries, Phnom Penh (S. Tum); World

Health Organization Collaborating Centre for Reference and

Research on Influenza, Melbourne, Victoria, Australia (Y.-M. Deng,

I. Barr); James Cook University, Cairns, Queensland, Australia

(P.F. Horwood); Food and Agriculture Organization of the United

Nations, Phnom Penh (K. Osbjer)

DOI: https://doi.org/10.3201/eid2406.172099
Cambodia is a lower-middle-income country in Southeast Asia with a large socioeconomic dependence on agriculture. In 2015, a total of $57 \%$ of all households in Cambodia had agricultural holdings, and $87 \%$ of these households raised poultry (4). Poultry are generally reared in backyards or on small-scale farms with minimal or no biosecurity. Therefore, poultry diseases such as HPAI can have devastating economic consequences. In 2013 alone, $\approx 25$ million chickens and 3.3 million ducks were either traded or disposed of (slaughtered for sale or died) in Cambodia. Of these, $22 \%$ of chickens and $18 \%$ of ducks were reported to have died from illness (5). Although control measures for HPAI in Cambodia include culling of poultry that is infected, suspected to be infected, or in contact with infected/suspected poultry, reporting is minimal, and no compensation mechanism exists. Since 2004, a total of 58 reported AIV outbreaks (mostly HPAI) have occurred in poultry and wild birds (as of April 2018), and 56 human influenza $\mathrm{A}(\mathrm{H} 5 \mathrm{~N} 1)$ cases (37 fatalities [case-fatality rate 66\%]) have been reported in Cambodia (6).

\section{The Study}

In early January 2017, a free-range production flock of 4-month-old Khaki Campbell ducks located in Kampong Thom Province in central Cambodia were found with loss of appetite, depression, weakness, white-bluish diarrhea, and swollen heads and eyes (Figure 1). Within days, $\approx 93 \%$ (an estimated 3,700 of 4,000) had succumbed to disease. The remainder of the flock was slaughtered. As part of a routine investigation into the causative agent, we obtained oropharyngeal and cloacal swab specimens and organs from 4 of the affected ducks. The National Animal Health and Production Research Institute of Cambodia performed initial screening for the presence of AIV by real-time quantitative reverse transcription PCR (qRT-PCR). The Institut Pasteur du Cambodge (IPC) verified the results and conducted further analysis.

IPC confirmed by qRT-PCR that 2 of 4 ducks were positive for influenza A virus. IPC successfully isolated viruses from both samples in embryonated chicken eggs (7) and designated them A/duck/Cambodia/b0116502/2017 and A/duck/Cambodia/b0120501/2017. Next, the World Health Organization's Collaborating Centre for Reference and Research on Influenza (Melbourne, VIC, Australia) 


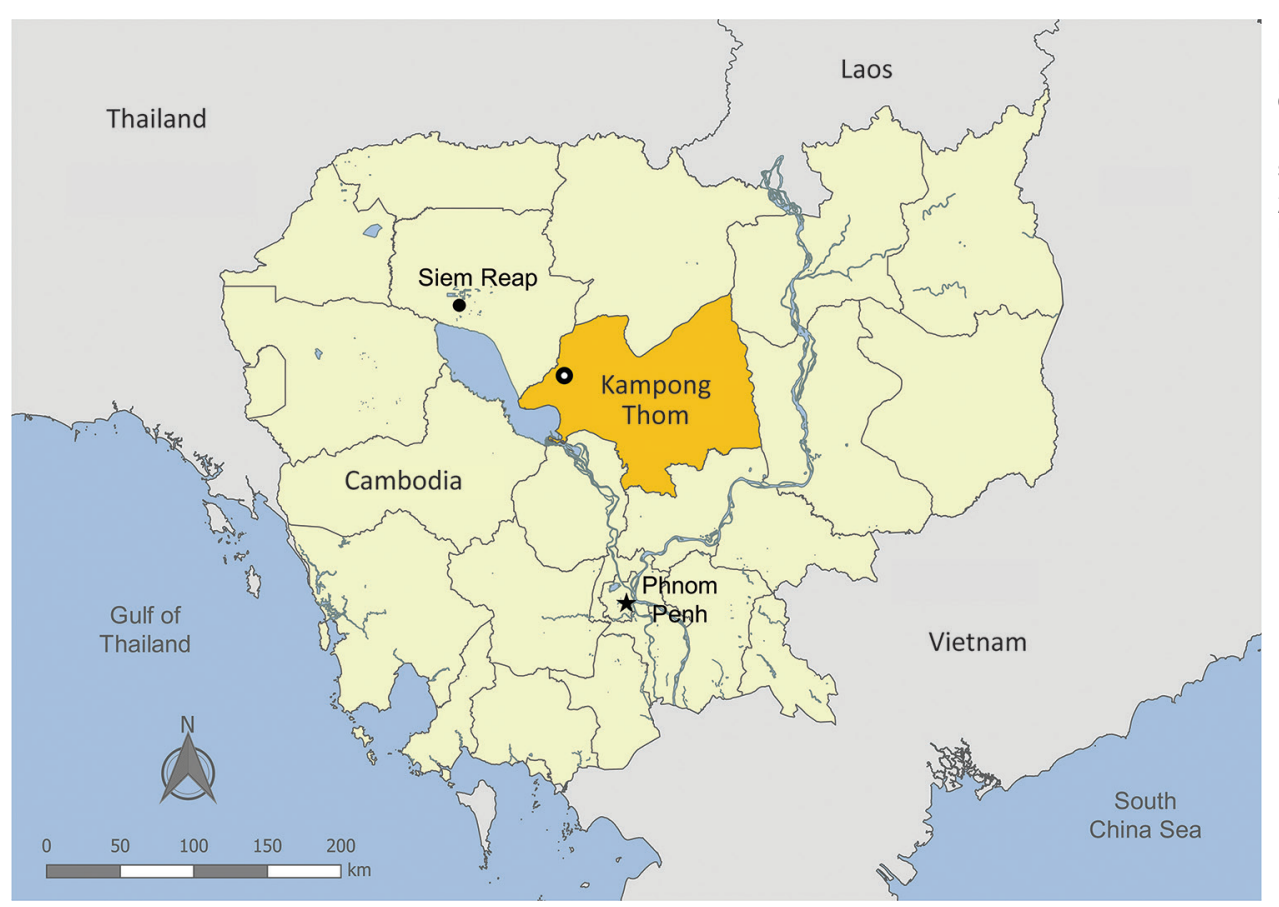

Figure 1. Location of duck mortality event and detection of influenza $A(H 7 N 3)$ virus in Kampong Thom Province (gold shading), Cambodia, January 2017. Open circle indicates exact location of the mortality event.

performed whole-genome sequencing on isolate RNA using the Ion Torrent next-generation sequencing (NGS) platform (Life Technologies, Carlsbad, CA, USA) and analyzed NGS data by using CLC Genomic Workbench 10 (https://www.qiagenbioinformatics.com/products/clcgenomics-workbench). Sanger sequencing with segmentspecific primers filled in any sequencing gaps (online Technical Appendix Table 1, https://wwwnc.cdc.gov/EID/ article/24/6/17-2099-Techapp1.pdf) using Big Dye Terminator Reaction Mix (Applied Biosystems, Foster City, CA, USA) on an ABI 3500xL Genetic Analyzer (Applied Biosystems). IPC, in conjunction with the World Health Organization's Collaborating Centre for Reference and Research on Influenza, used Geneious 9.1.8 (Biomatters Ltd., Auckland, New Zealand) to collate NGS and Sanger sequencing data, align strains, and analyze molecular markers. IPC submitted all sequences to GenBank (accession nos. MG591682-MG591697; online Technical Appendix Table 2). We used the maximum-likelihood method based on the general time-reversible model to infer phylogenic relationships and tree construction for each gene in MEGA version 7 (8) with 500 bootstrap replicates for robustness.

Sequencing revealed that both isolates belonged to the H7N3 subtype. Identification of $\mathrm{H} 7$ is not novel in Cambodia. Prior studies in 2013 and 2015 in live bird markets have identified low pathogenicity AIV (LPAIV) subtype $\mathrm{H} 7$ circulating in chickens and ducks $(6,7)$. Phylogenetic analyses indicated that all of the gene segments from both $\mathrm{H} 7 \mathrm{~N} 3$ isolates from Cambodia showed the highest degree sequence similarity to each other and fell into the Eurasian lineage of $\mathrm{H} 7$ viruses circulating in Asia, predominantly during 2012-2015. Neither strain shared genes with H7N9 viruses associated with human cases in China (Table 1; Figure 2; online Technical Appendix Figure 1-6). On a molecular level, we determined both isolates to be LPAIVs, showing a monobasic cleavage site, avian receptor specificity, and genetic indications of susceptibility to neuraminidase and matrix protein ion channel inhibitors (Table 2).

Because molecular data indicated that the $\mathrm{H} 7 \mathrm{~N} 3$ strains in this event were LPAIVs, these viruses were

\begin{tabular}{lcccc}
\hline \multicolumn{2}{l}{ Table 1. Sequence similarity between influenza A virus subtype H7N3 } & isolates and other influenza viruses, Cambodia* \\
\hline Gene segment & Strain with highest sequence identity & Position, nt & \multicolumn{1}{l}{ Identity, \% } & GenBank accession no. \\
\hline PB2 & A/duck/Hunan/S11682/2015(H7N9) & $1-2280$ & 97 & MF630450 \\
PB1 & A/duck/Hunan/S11682/2015(H7N9) & $1-2274$ & 97 & MF630451 \\
PA & A/duck/Jiangxi/15867/2013(H10N3) & $1-2151$ & 97 & KP285492 \\
HA & A/wild bird/Jiangxi/34458/2013(H7N7) & $1-1683$ & 97 & KP417103 \\
NP & A/duck/Nha Trang/84/2014(H6N6) & $1-1497$ & 98 & LC050632 \\
NA & A/duck/Vietnam/OIE-2329/2009(H11N3) & $4-1413$ & 94 & AB545596 \\
MP & A/duck/Hunan/S4443/2011(H11N9) & $1-982$ & 99 & CY146719 \\
NS & A/duck/Vietnam/HU1-16/2014(H11N7) & $1-838$ & $98 / 99$ & LC070024 \\
\hline
\end{tabular}

${ }^{*} \mathrm{HA}$, hemagglutinin; MP, matrix protein; NA, neuraminidase; NP, nucleoprotein; NS nonstructural; PA, polymerase; PB1, polymerase basic protein 1; PB2, polymerase basic protein 2 . 

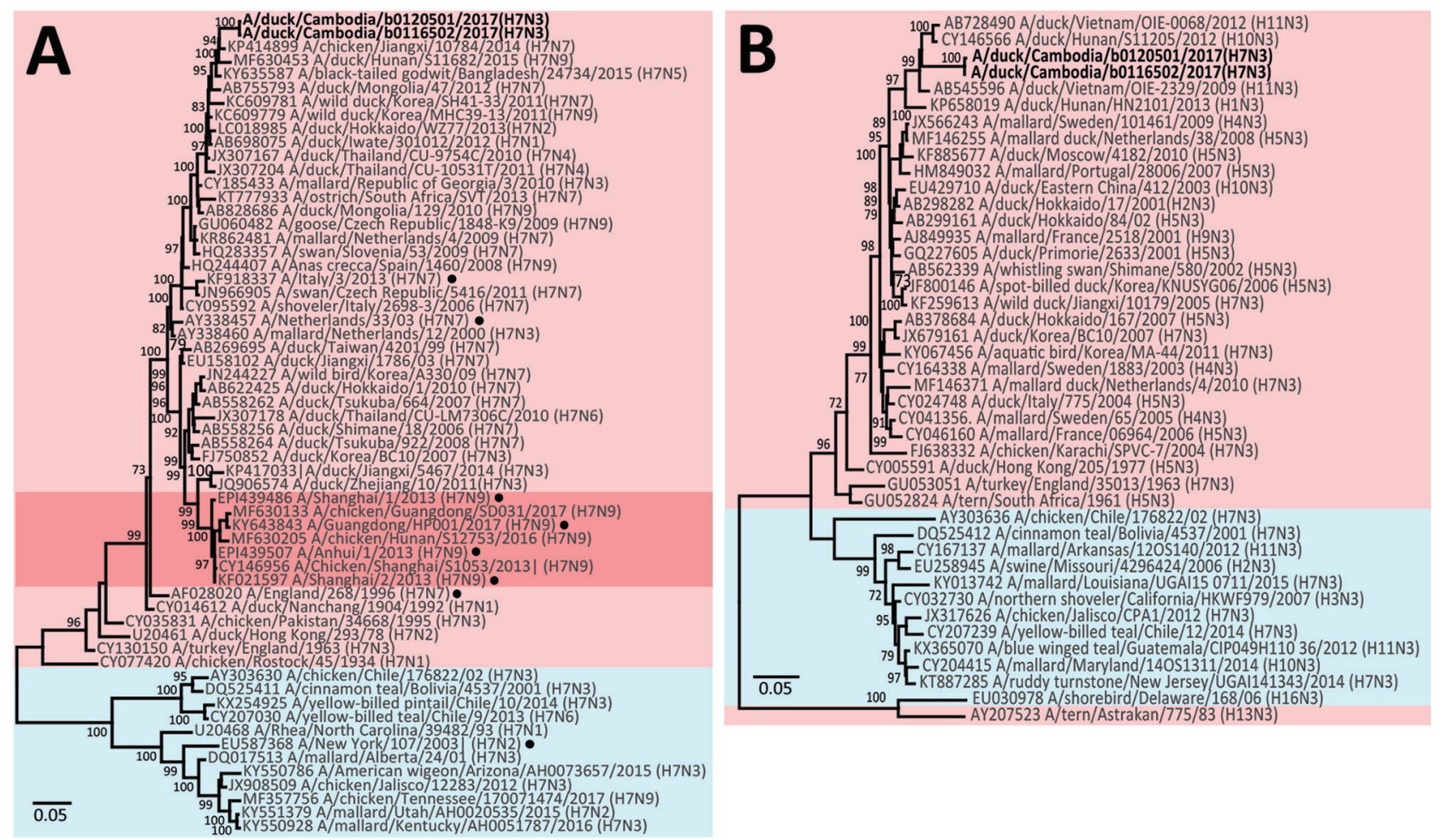

Figure 2. Phylogenetic analysis of the $H 7$ hemagglutinin $(H A)$ gene $(A)$ and $N 3$ neuraminidase $(N A)$ gene $(B)$ of influenza viruses isolated from ducks in Kampong Thom Province, Cambodia (boldface), and reference isolates. Trees were generated using the maximum-likelihood method based on the general time-reversible model. Bootstrap values $(n=500)>70$ are indicated. Light pink shading indicates strains from Eurasia, blue shading indicates strains from North and South America, and dark pink shading indicates H7N9 strains from China. Black dots indicate strains from human infections. GenBank accession numbers are provided for reference isolates. Scale bars indicate substitutions per site.

probably not the sole causative agent for such high mortality during this outbreak. However, infection with LPAIV H7N3 might have contributed to lethality by increasing susceptibility to secondary infections. In an effort to identify other possible pathogens, we screened swab samples and internal organs of the same ducks from the outbreak

\begin{tabular}{|c|c|c|c|c|}
\hline Gene segment and risk factor & $\begin{array}{l}\text { Amino acid } \\
\text { change }\end{array}$ & $\begin{array}{l}\text { Isolates in } \\
\text { Cambodia }\end{array}$ & Conclusions $†$ & Reference \\
\hline \multicolumn{5}{|l|}{ PB2 } \\
\hline Mammalian host range marker and increased viral pathogenicity & $\begin{array}{l}\text { E627K } \\
\text { D701N }\end{array}$ & $\begin{array}{l}E \\
D\end{array}$ & Avian specificity & (9) \\
\hline \multicolumn{5}{|l|}{$\mathrm{HA}$} \\
\hline $\begin{array}{l}\text { Multibasic cleavage site causing increased pathogenicity } \\
\text { Increased mammalian receptor specificity }\end{array}$ & $\begin{array}{l}\text { Multibasic } \\
\text { Q226L } \ddagger \\
\text { G228S } \ddagger\end{array}$ & $\begin{array}{l}\text { PEPPKGR/GLF } \\
\text { Q } \\
\text { G }\end{array}$ & $\begin{array}{c}\text { Monobasic } \\
\text { Avian specificity }\end{array}$ & $\begin{array}{l}(10) \\
(11)\end{array}$ \\
\hline \multicolumn{5}{|l|}{ NA } \\
\hline Resistance to NA inhibitor antivirals & $\begin{array}{c}\text { H275Y§ } \\
\text { E119Kग } \\
\text { R292K }\end{array}$ & $\begin{array}{l}\mathrm{H} \\
\mathrm{E} \\
\mathrm{R}\end{array}$ & $\begin{array}{l}\text { Sensitive to } \\
\text { oseltamivir }\end{array}$ & $(12)$ \\
\hline \multicolumn{5}{|l|}{ MP } \\
\hline Resistance to M2 inhibitor antivirals & $\begin{array}{l}\text { L26F } \\
\text { V27A } \\
\text { A30T } \\
\text { S31N } \\
\text { G34E }\end{array}$ & $\begin{array}{l}Q \\
R \\
D \\
V \\
G\end{array}$ & $\begin{array}{l}\text { Sensitive to M2 } \\
\text { inhibitors }\end{array}$ & $(13)$ \\
\hline
\end{tabular}

*HA, hemagglutinin; MP, matrix protein; MP2, matrix protein 2; NA, neuraminidase; PB2, polymerase basic protein 2.

†Receptor binding specificity and antiviral sensitivity is predicted based on sequence information and has not been experimentally confirmed. $\ddagger \mathrm{H} 3$ numbering.

$\S N 1$ numbering.

TN2 numbering. 
for the presence of anatid herpesvirus 1 (AnHV-1), commonly known as duck plague (14). Two of the 3 carcasses screened were positive for AnHV-1 in the liver; however, direct comparisons to swab samples cannot be made because no information was available on the correlation between swab samples and duck carcasses. AnHV-1 is known to cause high mortality in duck flocks globally, including in Cambodia, and co-infection with H7N3 virus and AnHV-1 might have contributed to the outbreak (15). From swab samples, we confirmed co-infection with AnHV-1 in the 2 H7N3 virus-positive ducks and 1 of the 2 H7N3 virus-negative ducks; however, our outbreak investigation revealed that ducks were retrospectively vaccinated against AnHV-1 with live attenuated vaccine once the flock began to show signs of illness. Consequently, because AnHV-1 vaccine can be detected by qRT-PCR up to 6 days postvaccination (14) and no specific date was available for vaccination before sample collection, no direct conclusions can be made about the associated contribution of AnHV-1 and H7N3 to the mass mortality during this outbreak. The extent and effect of such a co-infection need to be investigated further.

\section{Conclusions}

Given the endemicity of AIVs in Southeast Asia, especially in Cambodia, understanding the prevalence and effect of AIV in the region is vital. Although the $\mathrm{H} 7$ viruses identified during this outbreak were determined to be low pathogenicity and their role as causative agents of duck mortality remains unclear, continued active and passive surveillance, as well as molecular characterization and risk assessment, is crucial to identify, control, and prevent AIVs in this region. Further work is also necessary to understand the interplay of AIVs with other diseases of poultry to determine the etiology of bird mortality events in the region.

\section{Acknowledgments}

We thank the farmers for their cooperation with our study team, the laboratory and technical team from the Virology Unit at the Institute Pasteur in Cambodia, and the field teams from the National Animal Health and Production Research Institute (Cambodia Ministry of Agriculture, Forestry and Fisheries) and the Food and Agriculture Organization of the United Nations.

This study was funded, in part, under a cooperative agreement with the Office of the Assistant Secretary for Preparedness and Response in the US Department of Health and Human Services under grant number IDSEP140020-01-00 (http://www.asideproject.org) and by the World Health Organization. Its contents and conclusions are solely the responsibility of the authors and do not represent the official views of the US Department of Health and Human Services.
A.S. is funded by an Australian Government Research Training Program Scholarship and a Faculty of Science and Technology Research Scholarship from Federation University. The World Health Organization Collaborating Centre for Reference and Research on Influenza in Melbourne is supported by the Australian Government Department of Health.

\section{About the Author}

Ms. Suttie is a doctoral student at the School of Applied and Biomedical Sciences at Federation University, Australia. She is working on her $\mathrm{PhD}$ thesis in the Virology Unit at the Institut Pasteur du Cambodge on the molecular epidemiology of avian influenza in Cambodia.

\section{References}

1. Webster RG, Bean WJ, Gorman OT, Chambers TM, Kawaoka Y. Evolution and ecology of influenza A viruses. Microbiol Rev. 1992;56:152-79.

2. Freidl GS, Meijer A, de Bruin E, de Nardi M, Munoz O, Capua I, et al.; FLURISK Consortium. Influenza at the animalhuman interface: a review of the literature for virological evidence of human infection with swine or avian influenza viruses other than A(H5N1). Euro Surveill. 2014;19:20793. http://dx.doi.org/10.2807/1560-7917.ES2014.19.18.20793

3. Food and Agriculture Administration of the United Nations. H7N9 situation update. 2017 Nov 24 [cited 2017 Nov 25]. http://www.fao.org/ag/againfo/programmes/en/empres/h7n9/ situation update.html

4. National Institute of Stastistics, Ministry of Planning. Cambodia Socio-Economic Survey 2015 [cited 2017 Nov 20]. https://www.nis.gov.kh/nis/CSES/Final\%20Report\%20CSES\%20 2015.pdf

5. National Institute of Statistics, Ministry of Planning. Census of Agriculture in Cambodia, 2013 [cited 2017 Nov 24]. https://www.nis.gov.kh/nis/CAC2013/CAC_2013_Preliminary_ En.pdf

6. Horwood PF, Horm SV, Suttie AYP, Rith S, Sorn S, et al. Co-circulation of influenza $\mathrm{A} / \mathrm{H} 5 \mathrm{~N} 1$ with $\mathrm{H} 7$ and $\mathrm{H} 9$ viruses in Cambodian live bird markets with evidence of frequent co-infections in poultry. Emerg Infect Dis. 2018;24:352-5. http://dx.doi.org/10.3201/eid2402.171360

7. Horm SV, Tarantola A, Rith S, Ly S, Gambaretti J, Duong V, et al. Intense circulation of A/H5N1 and other avian influenza viruses in Cambodian live-bird markets with serological evidence of sub-clinical human infections. Emerg Microbes Infect. 2016;5:e70. http://dx.doi.org/10.1038/emi.2016.69

8. Kumar S, Stecher G, Tamura K. MEGA7: Molecular Evolutionary Genetics Analysis version 7.0 for bigger datasets. Mol Biol Evol. 2016;33:1870-4. http://dx.doi.org/10.1093/molbev/ msw054

9. Hatta M, Gao P, Halfmann P, Kawaoka Y. Molecular basis for high virulence of Hong Kong H5N1 influenza A viruses. Science. 2001;293:1840-2. http://dx.doi.org/10.1126/ science. 1062882

10. Abdelwhab EM, Veits J, Ulrich R, Kasbohm E, Teifke JP, Mettenleiter TC. Composition of the hemagglutinin polybasic proteolytic cleavage motif mediates variable virulence of H7N7 avian influenza viruses. Sci Rep. 2016;6:39505. http://dx.doi.org/10.1038/srep39505

11. Srinivasan K, Raman R, Jayaraman A, Viswanathan K, Sasisekharan R. Quantitative description of glycan-receptor binding 
of influenza A virus H7 hemagglutinin. PLoS One. 2013;8:e49597. http://dx.doi.org/10.1371/journal.pone.0049597

12. Song M-S, Marathe BM, Kumar G, Wong S-S, Rubrum A, Zanin $\mathrm{M}$, et al. Unique determinants of neuraminidase inhibitor resistance among N3, N7, and N9 avian influenza viruses. J Virol. 2015;89:10891-900. http://dx.doi.org/10.1128/JVI.01514-15

13. Abed Y, Goyette N, Boivin G. Generation and characterization of recombinant influenza $\mathrm{A}(\mathrm{H} 1 \mathrm{~N} 1)$ viruses harboring amantadine resistance mutations. Antimicrob Agents Chemother. 2005;49:5569. http://dx.doi.org/10.1128/AAC.49.2.556-559.2005

14. Qi X, Yang X, Cheng A, Wang M, Guo Y, Jia R. Replication kinetics of duck virus enteritis vaccine virus in ducklings immunized by the mucosal or systemic route using real-time quantitative PCR. Res Vet Sci. 2009;86:63-7. http://dx.doi.org/ 10.1016/j.rvsc.2008.05.001

15. Borin K, Samkol P, Thieme O. Investigation of duck production and hatcheries and duckling supply in Cambodia. AHBLpromoting strategies for prevention and control of HPAI. Rome: Food and Agriculture Administration of the United Nations; 2009 [cited 2017 Nov 25]. http://www.fao.org/docrep/013/al679e/ al679e00.pdf

Address for correspondence: Philippe Dussart, Institut Pasteur du Cambodge, Virology Unit, PO Box 983, 5 Monivong Blvd, Phnom Penh, Cambodia; email: pdussart@pasteur-kh.org

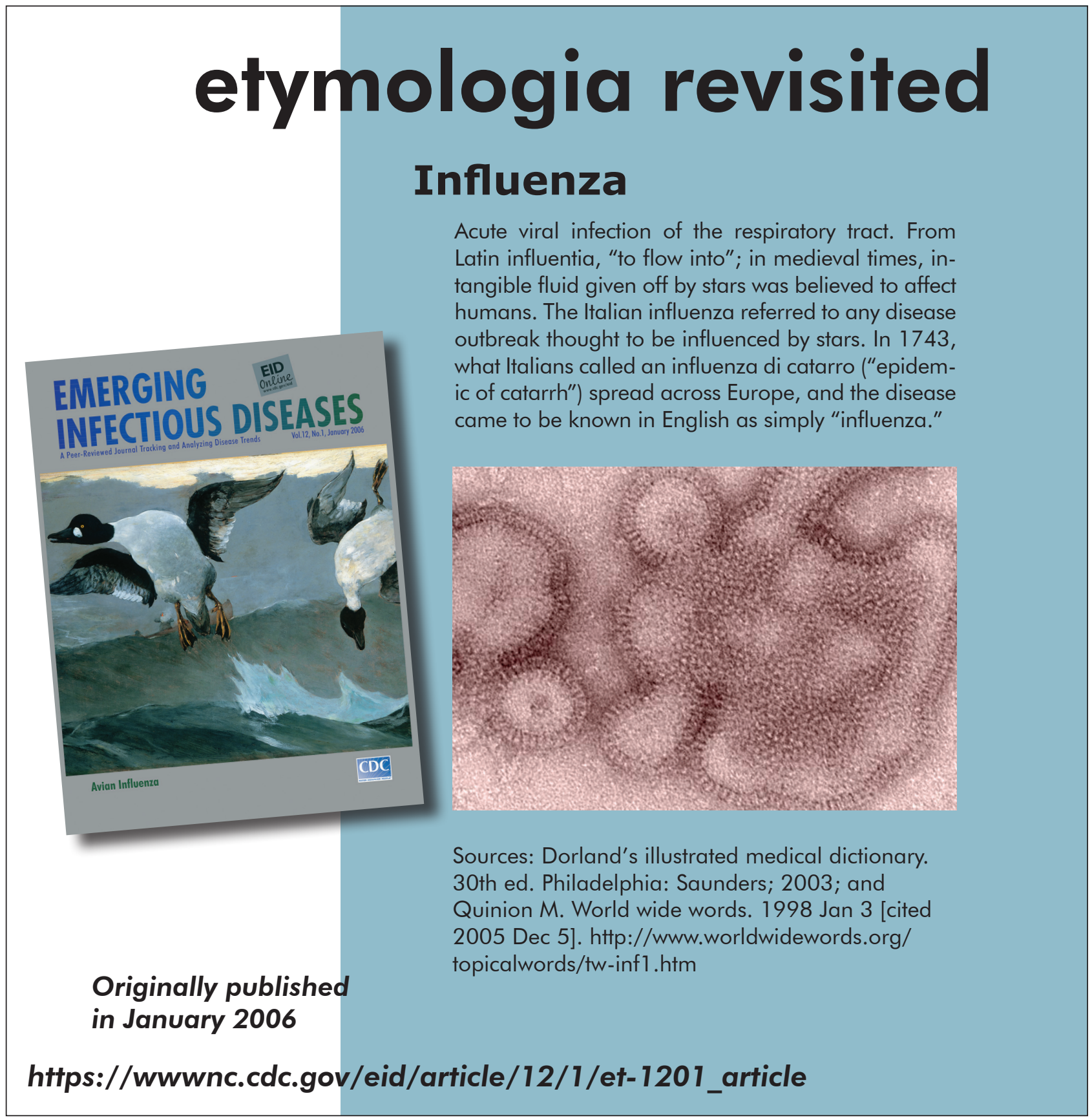

